\title{
Termination of Pregnancy with Pseudomyxoma Peritonei Secondary to Ovarian Mucinous Adenocarcinoma: A Video Case Report
}

\author{
Abdalla Mousa ${ }^{1}$, Islam T Elkhateb ${ }^{2 *}$, Ahmed SA Soliman $^{3}$ and Mario Rizk ${ }^{2}$ \\ ${ }^{1}$ Department of Obstetrics \& Gynecology, Kasr Alainy Hospital, Cairo University, Egypt \\ ${ }^{2}$ Department of Obstetrics \& Gynecology, New Giza University School of Medicine, Egypt \\ ${ }^{3}$ Department of Pathology, National Research Center, Egypt
}

*Corresponding author: Islam T Elkhateb, Department of Obstetrics \& Gynecology, New Giza University School of Medicine, Giza, 12256, Egypt, Tel: (+20)-102-165-6385

\section{Description}

A 27-years-old primigravida, at 30 weeks of gestation, was transferred to our tertiary care obstetric centre. On initial assessment, she was found to have fever $\left(38.5{ }^{\circ} \mathrm{C}\right)$, dyspnoea (26 breaths per minute), altered mental status (drowsiness), tachycardia (110 beat per minute) and hypotension $(80 / 50 \mathrm{mmHg})$. The patient started feeling sick following percutaneous ultrasound (US) guided ovarian cyst aspiration that was performed at an outpatient clinic 2 days before her presentation. Basically, the condition started 15 weeks ago when she had laparoscopic ovarian cyst aspiration done for an enlarged ovarian cyst with pregnancy. The aspirated fluid was not sent for cytology examination. A week before her presentation, she had acute abdominal distension, discomfort and constipation. Her Gynaecologist performed an US guided ovarian cyst aspiration five days ago with no improvement. She then had a second aspiration session two days ago that was followed by deterioration of her general condition.

The patient was admitted to our intermediate intensive care unit (ICU) laboratory work-up (Table 1) results were consistent with sepsis and disseminated intravascular coagulopathy (DIC) [1]. Three-dimensional (3D) US showed a huge multilocular left ovarian cyst $(20 \mathrm{~cm})$ with smooth outline and contents showing heterogeneous echogenicity. No solid components or papillary projections were detected in the cyst. It also showed pelvi-abdominal ascites reaching the level of hepatorenal pouch. Otherwise, pregnancy was intact with a viable average-for-gestational age foetus, normally implanted placenta and normal amniotic fluid volume. Trial of conservative management with parenteral antibiotics, intravenous (IV) fluids, hemodynamic and respiratory support was initiated [1]. The patient's vital signs and mental status did not improve following these measures, but rather started slowly deteriorating. Additionally, the patient had severe oliguria, as shown by urine output in her catheter. Therefore, the patient was transferred to the operation room (OR). This was few hours after her admission. Of note, the patient was given 12 milligrams of betamethasone (Betafos, Amoun, Cairo, Egypt) upon admission to improve foetal lung maturity $[2,3]$.

Under general anaesthesia in the OR, a low midline skin incision was performed. This was followed by a classical caesarean section (CS) with the delivery of a 30 weeks neonate that was transferred to neonatal intensive care unit (NICU). A huge left ovarian cyst was then identified and resected with the left ovary and tube after extension of the midline incision (Video 1). The ovarian cyst specimen was sent for histopathology examination. Given that the patient had evidence of DIC in her lab work, two units of fresh frozen plasma

Citation: Mousa A, Elkhateb IT, Soliman ASA, Rizk M (2021) Termination of Pregnancy with Pseudomyxoma Peritonei Secondary to Ovarian Mucinous Adenocarcinoma: A Video Case Report. Obstet Gynecol Cases Rev 8:204. doi.org/10.23937/2377-9004/1410204

Accepted: June 24, 2021: Published: June 26, 2021

Copyright: (C) 2021 Mousa A, et al. This is an open-access article distributed under the terms of the Creative Commons Attribution License, which permits unrestricted use, distribution, and reproduction in any medium, provided the original author and source are credited. 
Table 1: Patient work-up laboratory results consistent with sepsis and DIC.

\begin{tabular}{|l|l|l|l|}
\hline \multicolumn{2}{|l|}{ Laboratory test } & Result & Reference value for a $3^{\text {rd }}$ trimester \\
\hline Renal function tests & Urea $(\mathrm{mg} / \mathrm{dL})$ & 140 & $(17-43)$ \\
\hline & Creatinine $(\mathrm{mg} / \mathrm{dL})$ & 2.1 & $(0.5-0.9)$ \\
\hline \multirow{2}{*}{$\mathrm{CBC}$} & $\mathrm{Hb}(\mathrm{g} / \mathrm{dL})$ & 9.8 & $(9.5-13)$ \\
\hline & $\mathrm{HCT}(\%)$ & 29.9 & $(28-39)$ \\
\hline & $\mathrm{TLC}(\mathrm{K} / \mu \mathrm{L})^{*} 10^{3}$ & 50 & $(5.6-16)$ \\
\hline & $\mathrm{PLT}(\mathrm{K} / \mu \mathrm{L}))^{*} 10^{3}$ & 80 & $(150-400)$ \\
\hline Coagulation profile & $\mathrm{INR}$ & 2.5 & $\leq 1$ \\
\hline & $\mathrm{PT}(\mathrm{second})$ & 29 & $15-\mathrm{Nov}$ \\
\hline & $\mathrm{a}-\mathrm{PTT}(\mathrm{second})$ & 35 & $24-35$ \\
\hline Fibrinogen $(\mathrm{Mg} / \mathrm{DI})$ & & 160 & $300-700$ \\
\hline D-Dimer $(\mathrm{Ng} / \mathrm{MI})$ & & 1927 & $130-1700$ \\
\hline
\end{tabular}

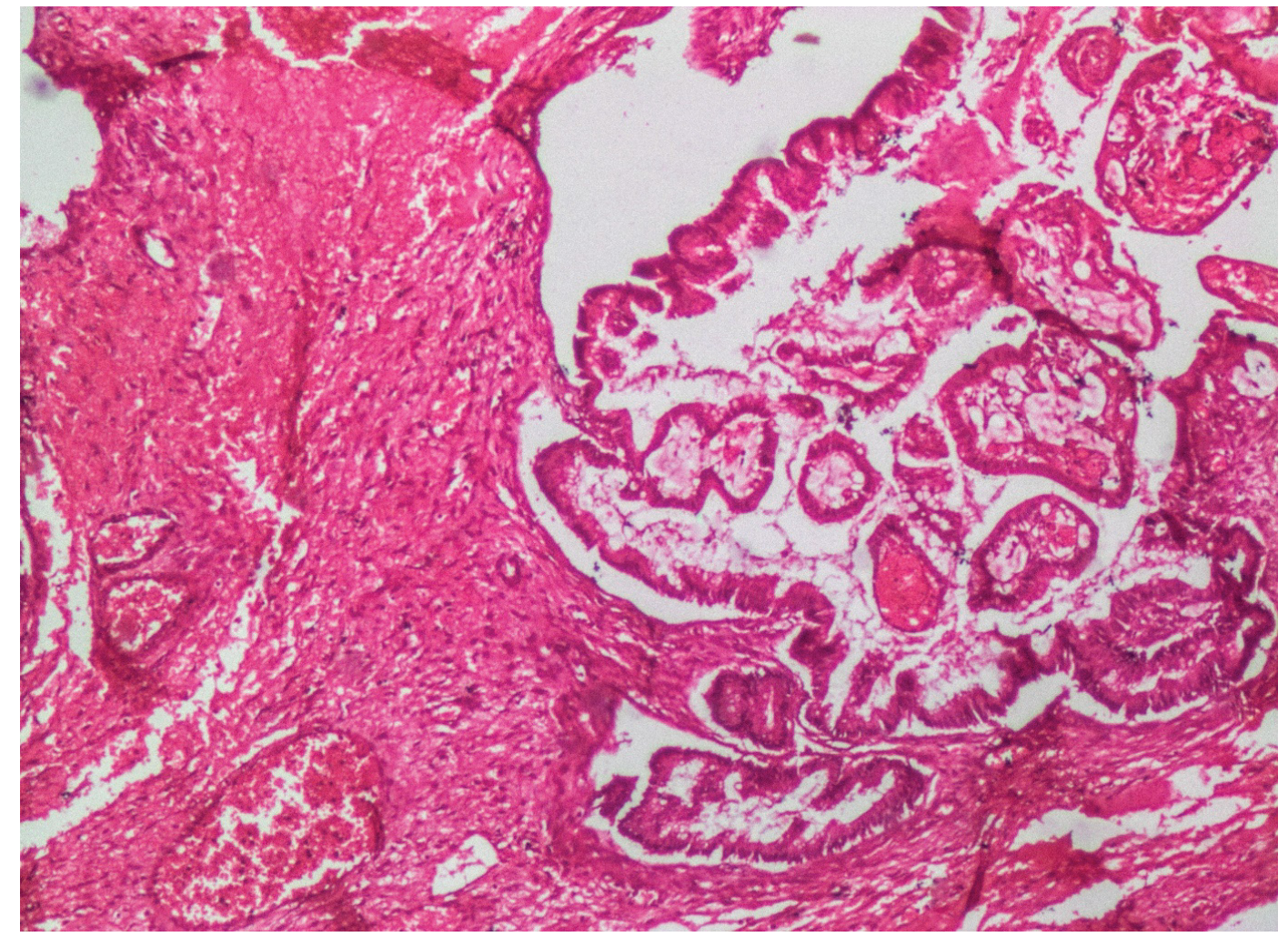

Figure 1: Ovarian mass showing irregular invasive glandular structures surrounded by extracellular mucin (H\&E, original magnification $\mathrm{x} 40$ ).

(FFP) were transfused intraoperatively [1]. Two units of packed red blood cells were also transfused as the patient's haemoglobin level was $7.2 \mathrm{~g} / \mathrm{dl}$ with on-going intraoperative blood loss and vital instability [4].

Postoperative, the patient was transferred back to the ICU where her vital signs and urine output markedly improved. A prophylactic dose of low molecular weight heparin was initiated for thromboprophylaxis [1]. The patient had smooth postoperative recovery and was discharged at day 5 postoperative after her lab results approached normal values. Histopathology examination results of the excised cyst came back one week later with the diagnosis of invasive mucinous adenocarcinoma (Figure 1).
The patient was referred to the university cancer centre. She had recurrent ascites then. She was counselled about comprehensive surgical staging with fertility preservation versus complete staging laparotomy [5-7] and she chose the latter option. A total abdominal hysterectomy, right salpingooophorectomy, infracolic omentectomy, ascetic fluid aspiration, peritoneal biopsies, bilateral pelvic and paraaortic lymph nodes sampling were performed $[7,8]$. She also had an appendectomy [9]. Specimens were sent for tissue histopathology and fluid cytology examination. No intra-abdominal organs or peritoneal masses that might require cytoreduction were detected intraoperatively $[7,8]$. The histopathology examination of these specimens came back free of 


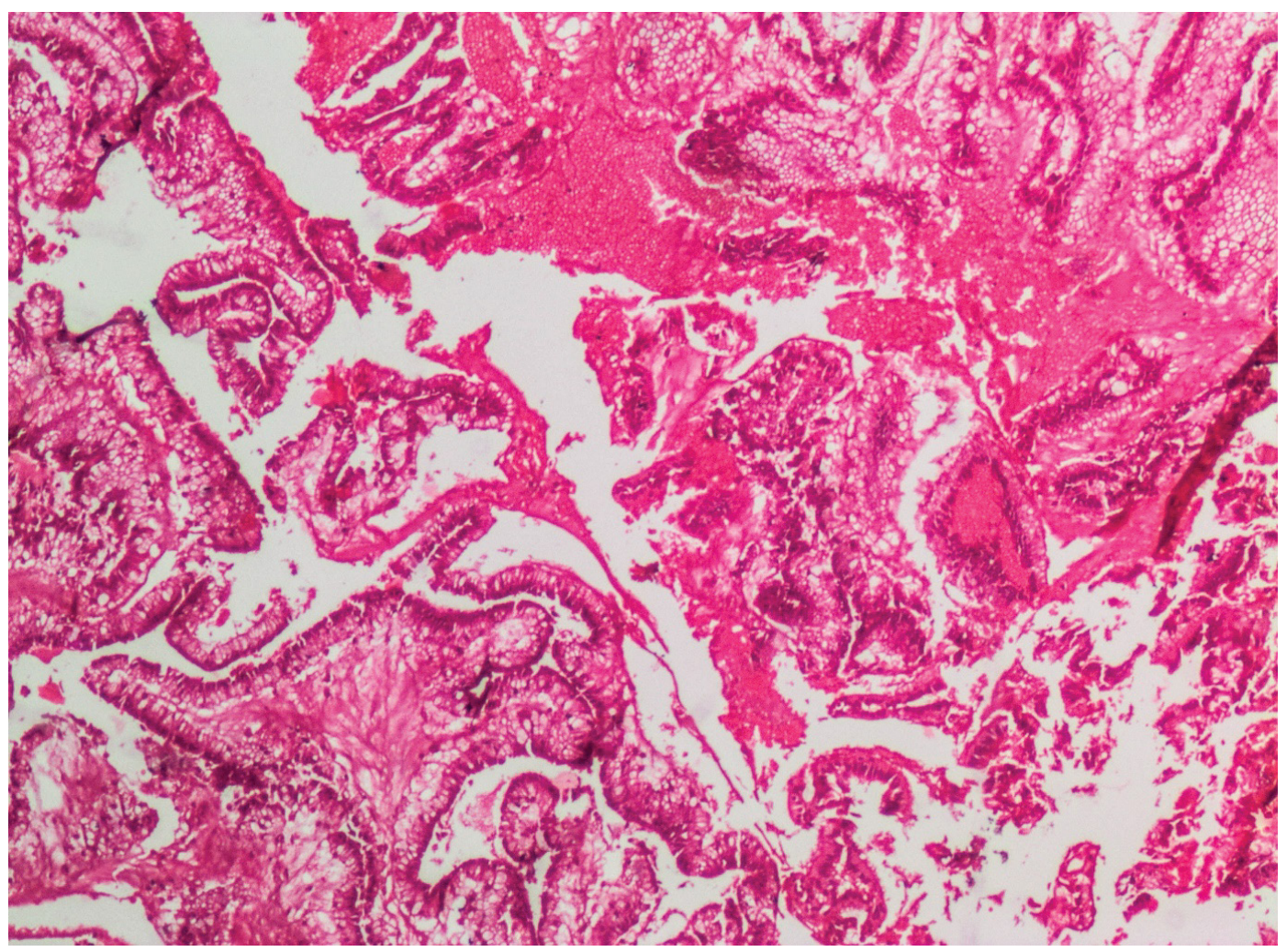

Figure 2: Pseudomyxoma showing irregular glandular and villous structures lined by tall columnar cells with basal elongated hyperchromatic nuclei and surrounded by wide areas of haemorrhage and focal extracellular mucin accumulation (H\&E, original magnification $\times 40$ ).

malignancy. However, the cytological examination of the ascetic fluid revealed neoplastic epithelial cells on a mucin background, constituting what is known as 'pseudomyxoma peritonei" [10] (Figure 2). Accordingly, ovarian cancer was upstaged to IC3 according to the international federation of gynaecology and obstetrics (FIGO) staging system $[7,11]$. The patient was scheduled for adjuvant postoperative chemotherapy to reduce the recurrence rate and improve overall survival $[12,13]$. This was done after extensive counselling as well.

Regarding the patient's neonate, he was admitted at the NICU for 4 weeks due to respiratory distress, sepsis and jaundice. He was then discharged after improvement. Four weeks later, he was readmitted due to severe retinopathy of prematurity that required laser photocoagulation. He is currently stable and growing well.

Ovarian cancer is the most common gynaecologic malignancy to cause death. Epithelial ovarian cancers (EOCS) accounts for more than $90 \%$ of ovarian malignancies. Unfortunately, EOCs commonly have subacute onset. So, most patients present at a late stage the usual presentation is either abdominal distension or an ovarian cyst that is accidentally discovered during imaging done for another complain in the abdomen or pelvis. EOC is a histologic diagnosis with a few subtypes. The serous subtype constitutes more than $75 \%$ [8]. Primary mucinous EOC subtype (our case) is relatively rare $(3 \%)$, usually unilateral, presents at a young age and is a rare cause for pseudomyxoma peritonei $[10,14]$.
Expectant management of complex ovarian cysts and even pseudomyxoma peritonei with pregnancy has been described in literature [15-17]. Percutaneous US guided ovarian cyst aspiration has never been described as a type of this management though, particularly if cyst is suspicious or showing any neoplastic features. Aspiration of the cyst in this case can lead to spillage of malignant cells or introduction of infection with subsequent sepsis and DIC (as happened in our case). Furthermore, cytological examination of the aspirate has low sensitivity for detecting malignant cells. Finally, US-guided ovarian cyst aspiration is associated with high risk of recurrence [18].

Failed conservative management of the patient's condition necessitated intervention with termination of pregnancy and left salpingo-oophorectomy. This approach improved the patient's condition, saved the foetus and corrected the DIC. Surgical staging during the first surgery could have spared the patient having laparotomy twice. This could only be possible if the invasive mucinous nature of the cyst was known beforehand. Unfortunately, the cyst aspirate was never sent for cytological examination at any of the three previous sessions of ovarian cyst aspiration, which was an absolute iatrogenic and medico-legal error.

\section{Learning Points/Take Home Messages (2-3 Bullet Points)}

- Most patients with advanced epithelial ovarian 
cancers are managed using surgical staging and cytoreduction followed by adjuvant chemotherapy.

- US guided aspiration is not an efficient way of managing ovarian cysts, as all ovarian cysts carry the risk of malignancy.

- Histological examination of excised body tissue and cytological examination of fluid aspirates are very useful for diagnosis and management of various conditions.

\section{Disclosure of Interests}

All authors confirm they have no disclosures specific to this study.

\section{Authors Contribution}

The authors equally contributed to this manuscript.

\section{References}

1. Levi M, Toh CH, Thachil J, Watson HG (2009) Guidelines for the diagnosis and management of disseminated intravascular coagulation. $\mathrm{Br} \mathrm{J}$ Haematol 145: 24-33.

2. WHO (2015) WHO recommendation on use of either dexamethasone or betamethasone as the antenatal corticosteroid of choice (November 2015). The WHO Reproductive Health Library, World Health Organization, Geneva.

3. Norman M, Piedvache A, Borch K, Huusom LD, Bonamy AE, et al. (2017) Association of short antenatal corticosteroid administration-to-birth intervals with survival and morbidity among very preterm infants: Results from the EPICE cohort. JAMA Pediatr 171: 678-686.

4. Green L, Connolly C, Cooper TK, r G Cho, S Allard (2015) Blood transfusion in obstetrics, guideline no. 47. Royal college of obstetricians and gynaecologists, London.

5. Maltaris T, Boehm D, Dittrich R, Seufert R, Koelbl H (2006) Reproduction beyond cancer: A message of hope for young women. Gynecol Oncol 103: 1109-1121.

6. Marpeau O, Schilder J, Zafrani Y, Uzan C, Gouy S, et al. (2008) Prognosis of patients who relapse after fertilitysparing surgery in epithelial ovarian cancer. Ann Surg Oncol 15: 478-483.
7. (2019) National comprehensive cancer network. NCCN clinical practice guidelines in oncology. Ovarian cancer.

8. Desai A, Xu J, Aysola K, Qin Y, Okoli C, et al. (2014) Epithelial ovarian cancer: An overview. World J Transl Med 3: 1.

9. Rosendahl M, Oester LA, Hogdall CK (2017) The importance of appendectomy in surgery for mucinous adenocarcinoma of the ovary. Int J Gynecol Cancer 27: 430-436.

10. Lee KR, Scully RE (2000) Mucinous Tumors of the ovary: A Clinicopathologic study of 196 borderline tumors (of intestinal type) and carcinomas, including an evaluation of 11 cases with 'pseudomyxoma peritonei'. Am J Surg Pathol 24: $1447-1464$.

11. Prat J, FIGO Committee on Gynecologic Oncology (2014) Staging classification for cancer of the ovary, fallopian tube, and peritoneum. Int J Gynaecol Obstet 124: 1-5.

12. Elit L, Chambers A, Fyles A, Covens A, Carey M, et al. (2004) Systematic review of adjuvant care for women with stage I ovarian carcinoma. Cancer 101: 1926-1935.

13. Winter-Roach BA, Kitchener HC, Lawrie TA (2012) Adjuvant (post-surgery) chemotherapy for early stage epithelial ovarian cancer. Cochrane Database Syst Rev 2015: CD004706

14. Hart WR, Norris HJ (1973) Borderline and malignant mucinous tumors of the ovary. Histologic criteria and clinical behavior. Cancer 31: 1031-1045.

15. Koyama S, Tomimatsu T, Sawada K, Kanagawa T, Tsutsui T, et al. (2011) Pseudomyxoma peritonei originating from colorectal cancer during pregnancy. J Obstet Gynaecol Res 37: 254-285.

16. Haase E, Yoo D, Sugarbaker PH (2009) Management of appendiceal pseudomyxoma peritonei diagnosed during pregnancy. World J Surg Oncol 7: 48.

17. Domini D, Campagna G, Coianiz A, Ferrari P, Garofalo $S$, et al. (1999) Mucinous adenocarcinoma of the ovary in pregnancy. Minerva Ginecol 51: 99-101.

18. Zanetta G, Lissoni A, Torri V, Valle CD, Trio D, et al. (1996) Role of puncture and aspiration in expectant management of simple ovarian cysts: A randomised study. BMJ 313: 1110-1113. 